\title{
The ethical dilemma of coercion in psychiatry - a transcultural
} aspect

\section{Ahmed Okasha}

\author{
Address: Institute of Psychiatry - Ain Shams University, 3 Shawarby St Kasr El Nil, Cairo 11211, Egypt \\ from WPA Thematic Conference. Coercive Treatment in Psychiatry: A Comprehensive Review \\ Dresden, Germany. 6-8 June 2007 \\ Published: 19 December 2007 \\ BMC Psychiatry 2007, 7(SuppI I):S3 doi:I0.II86/I47I-244X-7-SI-S3
}

This abstract is available from: http://www.biomedcentral.com/I47I-244X/7/SI/S3

(C) 2007 Okasha; licensee BioMed Central Ltd.

Coercion, compulsory admission, and the involuntary treatment of the mentally ill are among the most controversial issues in mental health care and are the subject of ongoing debate among patients, mental health care professionals, and a wider public. Physical restraint, seclusion, the involuntary application of neuroleptic drugs, and numerous other forms of compulsorily applied treatments are an essential part of mental health care all over the world. The practices of applying coercive measures also vary internationally according to cultural and legal traditions. Certain human problems are psychiatric diseases which, like other medical illnesses, are biological but, unlike other medical illnesses, can be treated with confinement and coercion! Religious beliefs have a strong influence on ethics, morals, and deontological mistakes. Although there are diverse cultures, only one human conscience, one human sense of responsibility, and one human moral obligation exist. Individual autonomy is valued in Scandinavian, European, and American cultures but is not empowering for the traditional, family-centered societies in Arab, sub-Saharan African, Indian, and Japanese cultures. This difference may affect the use of involuntary admission, informed consent, among other practices, in traditional versus Western Societies. The paper will discuss the transcultural ethical aspects of implementing coercive management of psychiatric disorders. 